\title{
Impact of Psychotropic Medication Effects on Obesity and the Metabolic Syndrome in People With Serious Mental Illness
}

\author{
Victor Mazereel ${ }^{1,2 \dagger}$, Johan Detraux ${ }^{2 \dagger}$, Davy Vancampfort ${ }^{2,3}$, Ruud van Winkel ${ }^{1,2}$ \\ and Marc De Hert ${ }^{1,2,4^{*}}$ \\ ${ }^{1}$ Department of Neurosciences, Center for Clinical Psychiatry, KU Leuven, Leuven, Belgium, ${ }^{2}$ University Psychiatric Center, \\ KU Leuven, Kortenberg, Belgium, ${ }^{3}$ Department of Rehabilitation Sciences, KU Leuven, Leuven, Belgium, ${ }^{4}$ Antwerp Health \\ Law and Ethics Chair, AHLEC University Antwerpen, Antwerp, Belgium
}

OPEN ACCESS

Edited by:

Katherine Samaras, St Vincent's Hospital Sydney,

Australia

Reviewed by:

Caterina Conte,

Università telematica San Raffaele,

Tarunveer Singh Ahluwalia, Steno Diabetes Center Copenhagen (SDCC),

Denmark

*Correspondence: Marc De Hert marc.dehert@upckuleuven.be

${ }^{\dagger}$ These authors share first authorship

Specialty section: This article was submitted to Obesity,

a section of the journa

Frontiers in Endocrinology

Received: 17 June 2020 Accepted: 23 September 2020 Published: 09 October 2020

Citation:

Mazereel V, Detraux J, Vancampfort $D$, van Winkel $R$ and De Hert M (2020) Impact of Psychotropic Medication

Effects on Obesity and the

Metabolic Syndrome in People With Serious Mental Illness.

Front. Endocrinol. 11:573479. doi: 10.3389/fendo.2020.573479
People with serious mental illness (SMI), including schizophrenia, bipolar disorder, and major depressive disorder, have a higher mortality rate and shortened life expectancy. This is mainly attributable to physical diseases, particularly cardiovascular diseases (CVDs). Important risk factors for CVDs are obesity and other metabolic abnormalities, which are especially prevalent in people with SMI. Several factors contribute to this increased risk, including unhealthy lifestyles. Psychotropic medication independently further increases this risk. In this review we want to examine the relationship between obesity and other components of the metabolic syndrome and psychotropic medication in people with SMI.

Keywords: obesity, mood stabilizer, metabolic syndrome, serious mental illness, antipsychotic, antidepressant

\section{INTRODUCTION}

People with serious mental illness (SMI), including schizophrenia, bipolar disorder (BD), and major depressive disorder (MDD), have a two to three times higher mortality rate than the general population and a 10-20 years reduced life expectancy that appears to be widening (1-9). The majority of deaths in persons with SMI are due to physical diseases, predominantly cardiovascular diseases (CVDs) $(10,11)$. Despite major advances in cardiovascular health promotion and disease prevention during the last decade, current evidence suggests a limited improvement of CVD risk factors in SMI patients (12). Although a genetic burden, inducing accelerated aging, partly explains the observed premature mortality from physical diseases (9), tackling modifiable CVD risk factors could extend life expectancy.

Obesity and other metabolic abnormalities are important risk factors for CVDs. Obesity is a worldwide problem with estimates of overweight and obesity of $36.9 \%$ for men and $38 \%$ for women around the globe (13). Compared with people with a body mass index (BMI) of $22.5-25 \mathrm{~kg} / \mathrm{m}^{2}$, the median survival is reduced by $2-4$ years for people with a BMI of $30-35 \mathrm{~kg} / \mathrm{m}^{2}$ and by $8-10$ years for those with a BMI of $40-45 \mathrm{~kg} / \mathrm{m}^{2}$ (14).

Metabolic abnormalities are especially prevalent in people with SMI. Genetic (15) and nonmedical factors, including unhealthy lifestyles and disparities in the health care $(6,7)$, contribute to this increased prevalence. However, the use of psychotropic medication (antipsychotics, antidepressants and mood stabilizers) can further increase the risk of metabolic abnormalities in 
these patients $(1,11)$. Here we will give an overview of the relationship between obesity and other components of the metabolic syndrome and psychotropic medication in people with SMI.

\section{OBESITY}

People with SMI are more likely to have overweight or to develop obesity, compared to people who don't have a mental illness (1, $11,16)$. The risk for obesity can be more than four times higher in patients with schizophrenia and about one and a half times higher in those with $\mathrm{MDD}$ or $\mathrm{BD}$, compared to the general population (1). Overall, the proportion of SMI patients with abdominal obesity lies between 50 and $63 \%$, depending on the employed criteria (16). Lifestyle factors, such as physical inactivity and an unhealthy diet, as well as psychotropic medication contribute to obesity in these patients (17).

\section{Effect of Psychotropic Medication on Obesity}

Weight gain (at least 7\% body weight gain from baseline) (13) is a well-established side-effect of almost all antipsychotics $(1,18)$. Antipsychotic medications, however, differ in their weight gain liability (11, 18-20) (Table 1). The second-generation antipsychotics (SGAs) clozapine and olanzapine appear to have the greatest potential to induce weight gain. Quetiapine, risperidone, paliperidone and iloperidone are associated with a moderate risk for weight gain. Aripiprazole, amisulpride, ziprasidone, asenapine and lurasidone have less or little effect on body weight. Among the first-generation antipsychotics (FGAs) chlorpromazine and thioridazine are reported to induce more weight gain than haloperidol. No antipsychotic should be considered truly weight neutral, as virtually all antipsychotics are associated with weight gain after prolonged use, compared with placebo $(1,11,18,19,21,22)$. However, substantial differences exist between individuals in their susceptibility to gain or lose weight with the same antipsychotic $(18,23)$.

Compared to antipsychotics, weight gain with antidepressants is generally more modest or mild, and differences between antidepressants are small $(1,24)$ (Table 1). Considering antidepressants in patients with MDD, long-term use ( $>6$ months) and polypharmacy of antidepressants, such as the tricyclic antidepressant (TCA) amitriptyline, the tetracyclic mirtazapine and the selective serotonin reuptake inhibitor (SSRI) paroxetine have been associated with weight gain of up to $2.7 \mathrm{~kg}(25-28)$. Bupropion is more likely to cause weight loss than gain $(-1.9 \mathrm{~kg})(27-29)$. Nevertheless, the effect of each antidepressant on weight gain can vary across individuals, especially in the long term.

The effect of mood stabilizers on weight gain in $\mathrm{BD}$ patients is significant, but also to a lesser degree than with the use of antipsychotics $(1,30)$ (Table 1). Weight gain is more frequent with lithium than placebo $(\mathrm{OR}=1.89)(31)$, with a reported $77 \%$ of patients experiencing an average weight gain of 4-6.3 kg (32, 33). The most drastic weight changes with lithium occur during the first two years, with higher body weight at the start predicting higher weight increase (33). This is believed to result from increased appetite, hypothyroidism and nephrogenic diabetes insipidus leading to increased thirst (34). Considering antiepileptic mood stabilizers, the use of valproate is associated with weight gain in up to $50 \%$ of patients and can be detected 2-3 months after initiation (35). Patients gain on average $6.4 \mathrm{~kg}(32)$. This finding does not appear to be dose dependent $(36,37)$. Carbamazepine has a lower risk of weight gain (38). Lamotrigine at higher doses and topiramate are associated with weight loss of up to $1.2 \mathrm{~kg}(32,35)$. There is currently little evidence supporting the efficacy of combining metformin with a mood stabilizing treatment on weight loss (35).

\section{Effects of Psychotropic Medications by Age}

A greater magnitude of weight gain following exposure to antipsychotic medication has been reported in children and adolescents (<18 years old) (39). The rank order of weight gain liability of antipsychotics in this vulnerable population remains roughly the same. Olanzapine has been associated with the highest risk of significant weight gain. Risperidone has a somewhat lower tendency to cause weight gain, while aripiprazole has a minor impact on body weight $(1,40-43)$. The extent of weight gain is also higher in first-episode patients $(18,22)$, with a mean weight gain of $3.22 \mathrm{~kg}$ during short term $(<12$ weeks) and $5.30 \mathrm{~kg}$ during long-term (>12 weeks) treatment (22). Once again, olanzapine seems to induce significantly more

TABLE 1 | Impact of psychotropic medication on obesity and other metabolic abnormalities in people with SMI.

\begin{tabular}{|c|c|c|c|}
\hline Condition & Antipsychotics & Antidepressants & Mood stabilizers \\
\hline Obesity & $\begin{array}{l}\text { O/+ (for haloperidol, lurasidone, ziprasidone, amisulpride, asenapine, } \\
\text { aripiprazole) to +++ (for clozapine, olanzapine, low potency FGAs) }\end{array}$ & $\begin{array}{l}\text { - (bupropion) to }+ \\
\text { (mirtazapine, paroxetine, } \\
\text { TCAs) }\end{array}$ & $\begin{array}{l}\text { 0/- (lamotrigine, topiramate) to ++ (lithium, } \\
\text { valproate) }\end{array}$ \\
\hline Dyslipidemia & $\begin{array}{l}\text { 0/- (cariprazine, aripiprazole, brexpiprazole) to + (clozapine, olanzapine, } \\
\text { risperidone, quetiapine) }\end{array}$ & 0 to + (if weight gain) & $\begin{array}{l}\text {-/0 (valproate: reduction in cholesterol, } \\
\text { increase in triglycerides) to + (lithium) }\end{array}$ \\
\hline Hypertension & 0 to + (if weight gain) & $\begin{array}{l}0 \text { (SSRIs) to + (SNRIs, } \\
\text { bupropion and TCAs) }\end{array}$ & 0 \\
\hline Diabetes & $\begin{array}{l}\text { 0/+ (for lurasidone, ziprasidone, amisulpride, aripiprazole) to +++ (for } \\
\text { clozapine, olanzapine) }\end{array}$ & $-/ 0$ (SSRIS) to ++ (TCAs) & $\begin{array}{l}\text {-/0 (lithium, lamotrigine, oxcarbazepine) to } \\
+ \text { (valproate) }\end{array}$ \\
\hline
\end{tabular}

-, reduction; 0, generally no effect; +, some effect; ++, moderate effect; +++, marked effect; ?, uncertain.

FGA, first-generation antipsychotics; TCAs, tricyclic antidepressants; SSRls, selective serotonin reuptake inhibitors; SNR/s, serotonine and norepinephrine reuptake inhibitors. Table adapted and updated from Correll (1) with permission of the authors. 
long-term (>12 weeks) weight gain in these patients, compared to other antipsychotic medications (22).

In the $\mathrm{BD}$ pediatric population a similar trend with mood stabilizers is apparent as in the adult population, however, with less weight gain than antipsychotic therapy. Mood stabilizers lead to an average increase of $1.2 \mathrm{~kg}$ over 12 weeks (44).

\section{Effects of Psychotropic Medications Over Time}

People with SMI often quickly gain weight during the first few weeks of antipsychotic treatment. This rapid increase in weight then gradually decreases and flattens within one year. Initial rapid weight gain is a good predictor for significant long-term weight gain and other metabolic abnormalities. A cohort study with 170 first-episode psychosis patients reported a total mean weight gain of $12.1 \mathrm{~kg}$ three years after the initiation of treatment (45). Eighty-five percent of the total weight gain occurs in the first treatment year (30). Switching to an antipsychotic with a lesser tendency to cause weight gain can be an effective intervention for some, but not all patients (18).

\section{Mechanisms of Medication-Induced Weight Gain}

Antipsychotic-induced weight gain/obesity probably occurs as a result of increasing appetite and food intake, as well as delayed satiety signaling. Antagonism at the serotoninergic 5-HT2C and histaminergic $\mathrm{H} 1$ receptors has been identified as the key mechanism contributing to this side-effect. Clozapine and olanzapine, having the highest weight gain liability, also have a very strong binding affinity to both 5-HT2C and $\mathrm{H} 1$ receptors (21). H1 antagonism has been identified as the strongest predictor of weight gain with antidepressants (31).

A decrease in caloric expenditure due to the sedative effects, and an increased intake of caloric beverages due to dry mouth/ throat induced by certain antipsychotics may also contribute to antipsychotic-induced weight gain.

Genetic factors play an important role in medication-induced weight gain, to be estimated at $60-80 \%$ for antipsychotic-related weight gain (32). This might help explain the interindividual variability in weight gain to psychotropic medication. In the field of pharmacogenetics, findings suggest the involvement of polymorphisms in several genes coding for proteins implicated in hypothalamic control of food intake and body weight, such as 5HT2C, dopamine D2 receptor, BDNF, insulin-induced gene, melanocortin 4 receptor, synaptosomal-associated protein, leptin, ghrelin and mitochondrial genes $(21,33,34)$.

\section{Management of Medication-Induced Weight Gain}

Individual lifestyle counseling, exercise interventions, psychoeducation, and augmentation with aripiprazole or topiramate are considered evidence-based options for the management of antipsychotic-induced weight gain (35). Recent meta-analytical evidence also shows that metformin might decrease weight in adults, adolescents, and children treated with SGAs, although additional high-quality evidence is needed. Moreover, treatment effects with metformin are small (around -3.2 kg over 12-16 weeks) and optimal dosage is unclear (36-38).

\section{Obesity, Genetics and Environmental Factors}

The complex interplay of genetic and lifestyle risk factors influence metabolic disease risk (44). Genome-wide association studies (GWAS) can successfully identify genetic associations with highly polygenic phenotypes in sufficiently large samples (46). Peters et al. (24) identified 40 loci which may contribute to genetic overlaps between mental disorders/traits and BMI and/or shape related phenotypes. Although a recent study of combined GWAS data from 1,380,284 individuals demonstrated an extensive genetic overlap between BMI and SMI, a different genetic liability to weight gain across these disorders seems to exist. While environmental causes of weight gain seem to be more important than disease-specific genetics in patients with schizophrenia, in patients with $\mathrm{MDD}$ or $\mathrm{BD}$ results point to genetic susceptibility as a more likely cause of weight gain. These finding suggest that factors such as medication, diet, or lifestyle may be the main drivers of weight gain in patient with schizophrenia (25).

\section{Effect of Obesity and Other Metabolic Abnormalities on Response to Psychotropic Medication}

Studies have shown that the presence of obesity or other metabolic abnormalities significantly affects treatment response outcomes in people with SMI. A 1-year naturalistic study by Woo et al. (26) found that the presence of obesity in patients with MDD was associated with a decreased treatment response to antidepressants $(\mathrm{OR}=1.55)$. Males with concurrent metabolic problems (i.e. the presence of one or more of hypertension, hyperglycemia, or hypercholesterolemia) had an even higher risk for insufficient response ( $O R=2.32)$. Benedetti et al. (27) showed that BMI can indirectly hamper antidepressant response by increasing the levels of proinflammatory cytokines in patients with $\mathrm{BD}$. This effect of BMI, however, was revealed only when considering cytokines.

\section{METABOLIC SYNDROME}

The metabolic syndrome (MetS) refers to the clustering of several cardiometabolic conditions, including abdominal obesity, glucose intolerance or insulin resistance, dyslipidemia [higher levels of triglycerides and decreased high-density lipoprotein (HDL) cholesterol levels], and hypertension (11). Several meta-analyses demonstrated that, compared with matched general population controls, people with SMI have a significantly increased risk for developing MetS. When pooling across SMIs, one in three has MetS and no significant difference between diagnostic categories of schizophrenia, BD and MDD can be found $(16,28,47)$.

Patients with schizophrenia are 2.35 times more likely to have MetS, compared to the general population, with a prevalence of 
$34.2 \%$ in multi-episode patients. MetS prevalence is significantly lower in drug-naïve (10\%) or first-episode patients (15.9\%), even after correcting for age $(\mathrm{p}<0.001)(29,48)$. Patients with BD are 1.98 times more likely to have MetS, with a prevalence rate of $37.4 \%$. BD patients taking antipsychotics have a higher chance of developing MetS than those who are antipsychotic free $(\mathrm{OR}=1.72)$ (49). The increased risk for MetS, however, extends to drug-naïve patients too (50). Looking at MetS risk according to type of antipsychotic, we see a similar pattern as the risk for obesity with clozapine (prevalence rate $=47.2 \%$ ), quetiapine (prevalence rate $=$ $37.3 \%$ ) and olanzapine (prevalence rate $=36.2 \%$ ) being associated with the highest, and aripiprazole (prevalence rate $=19.4 \%$ ) and amisulpride (prevalence rate $=22.8 \%$ ) with the lowest MetS risk (16). A recent review of systematic reviews showed that evidence is inconsistent regarding the metabolic side-effects of antipsychotic polypharmacy with some showing no difference to monotherapy and others showing a reduction in weight when combining with aripiprazole (51).

The overall proportion of MDD patients having MetS is $30.5 \%$ with an OR of 1.54 , when compared to control population (52). One factor contributing to this relationship are the depressive symptoms themselves, especially when vegetative symptoms are present $(53,54)$. Another factor might be antidepressant use, independent of depressive symptom severity, although not all studies confirm this finding (52, 55-58) (Table 1). Moreover, it is still unclear whether the potential increased risk associated with antidepressant use is caused by a single antidepressant class or is a common finding across classes. A recent review pointed to antidepressants with H1-receptor antagonist function to be the main culprit (53). As antipsychotics are often prescribed as augmentation strategy in the treatment of depression, they should be considered as a significant driver for MetS in this group as well (52).

\section{DYSLIPIDEMIA}

A meta-analysis showed that patients with SMI have a significantly increased risk for elevated triglycerides $(\mathrm{RR}=1.49)$ and decreased HDL-cholesterol $(\mathrm{RR}=1.33)$, compared to population controls (16). When compared with matched population controls, schizophrenia patients have a 2.73 times higher risk to have hypertriglyceridemia and a 2.35 times higher risk to have reduced HDL-cholesterol levels. In particular patients with multiepisode schizophrenia meet criteria for elevated triglycerides and low HDL-cholesterol more often than first-episode or untreated patients (respectively 39 vs. 10.5 and $23.3 \%$ for triglycerides and 41.7 vs. 16 and $24.2 \%$ for low HDL-cholesterol) (29). Interestingly, drug naïve first-episode patients also have dyslipidemia with a systematic review reporting lower levels of HDL and higher levels of triglycerides, compared to controls (59). A GWAS revealed that the levels of LDL- and HDL-cholesterol together with schizophrenia risk share common genetic risk factors (60).

A similar picture arises in patients with $\mathrm{BD}$ having higher total and LDL- and lower HDL-cholesterol levels $(16,61)$. Moreover, no significant differences seem to exist between schizophrenia and BD patients regarding HDL-cholesterol and triglycerides (28). Again, these abnormalities may already be present in drug-naïve $\mathrm{BD}$ patients (62). The lipid abnormalities in $\mathrm{BD}$ may be state dependent with depression resulting in more anomalous levels than mania (63).

A higher risk for hypertriglyceridemia (but not lower HDLcholesterol) was also found in patients with MDD, compared with age- and gender-matched general population controls (52). However, in another study with $\mathrm{BD}$ and MDD patients lower HDL- and higher total and LDL-cholesterol was found during the depressive episode (61). This suggests that these lipid abnormalities might again be state dependent. Just as with schizophrenia, mood disorders and metabolic abnormalities might share common genetic risk factors (64).

Although dyslipidemia may precede the use of medication in patients with SMI, there is sufficient evidence showing that certain types of psychotropic medication can independently lead to further abnormalities (Table 1). Antipsychotics have been associated with lipid abnormalities $(10,23)$. Levels of triglycerides and cholesterol can increase during the early stage of antipsychotic treatment. These adverse effects, however, may even precede antipsychotic-induced weight gain, pointing to weight-independent molecular effects, in addition to weight-related ones (23). Clozapine, olanzapine and risperidone have all been associated with a higher chance of mild dyslipidemia, compared with FGAs such as haloperidol, although differences are small and one should focus more on the metabolic profile of each individual antipsychotic (65). A recent network meta-analysis showed that the increased total cholesterol with clozapine, olanzapine and quetiapine was moderated by race, with non-white participants having larger increases. Cariprazine decreased LDL-cholesterol, quetiapine and olanzapine increased LDL-cholesterol, brexpiprazole and aripiprazole increased HDL-cholesterol, and quetiapine, olanzapine, clozapine and zotepine increased triglycerides (20). Regarding antipsychotic polypharmacy, a systematic review reported better lipid profiles when the augmentation drug of choice was aripiprazole (51). This might therefore be a viable strategy to attenuate the detrimental effects of certain antipsychotics on lipid profiles.

Treatment with statins in schizophrenia patients decreases LDL-cholesterol, total cholesterol and triglycerides, but does not alter HDL-cholesterol (66-68). Other efficacious interventions for dyslipidemia are topiramate for LDL-cholesterol and triglycerides, and lifestyle interventions for total cholesterol, LDL-cholesterol and triglycerides (35).

Among mood stabilizers, lithium has not been associated with clinically relevant lipid abnormalities besides a mildly elevated increase in triglycerides (69). However, lithium-induced hypothyroidism can lead to weight gain and changes in lipid profile. Despite its association with weight gain and increased triglycerides, valproate has been correlated with reductions in total and LDL-cholesterol in patients with schizophrenia and BD (1). In children and adolescents with $\mathrm{BD}$, valproate does not appear to increase the risk of dyslipidemia and may in fact improve lipid profiles to some degree $(70,71)$. Carbamazepine is associated with a similar increase in both HDL- and LDLcholesterol (72). 
Although some antidepressants have been associated with weight gain, which is a risk factor for lipid abnormalities, data on adverse lipid effects with these medications remain scarce. At this moment, results show that most antidepressants have not been associated with dyslipidemia. Moreover, a direct weightindependent effect on serum cholesterol has not been consistently reported (1). When combining a SSRI with olanzapine, quetiapine or risperidone in patients with schizophrenia or BD a negligible increase is seen in total and LDL-cholesterol and triglycerides $(73,74)$.

\section{HYPERTENSION}

A meta-analysis found that, compared with matched general population controls, people with SMI do not seem to have a significantly increased risk for hypertension $(\mathrm{p}=0.07)(16,52)$. However, another recent meta-analysis in $\mathrm{BD}$ and schizophrenia patients did report an increased risk for hypertension in $\mathrm{BD}$ patients (Incidence Rate Ratio $=1.27$ ) (75). A recent large representative cohort study in Taiwan showed that schizophrenia patients were 1.93 times more likely to be diagnosed with hypertension in the year before schizophrenia was diagnosed (76). A possible explanation for the disparity in results is that blood pressure in $\mathrm{BD}$, schizophrenia and MDD patients is poorly recorded and that this may have led previous studies to underestimate the risk of hypertension in SMI patients $(75,77)$.

The literature on the appearance of hypertension due to antipsychotics seems to be restricted to case studies/series (78, 79). The largest existing cohort study, comprising 284,234 individuals, showed that those with 1 year of exposure to SGAs showed only a small heightened risk of essential hypertension (Hazard Ratio, HR $=1.16, \mathrm{p}<0.0001$ ), compared to those using antidepressants (80) (Table 1). Moreover, there does not seem to be an additive effect on blood pressure when combining antipsychotics (51). The possible small increased risk in hypertension after antipsychotic treatment probably can be attributed to antipsychotic-induced weight gain/obesity (81) and to the anti-dopaminergic effect of these agents, as all 5 dopamine receptor subtypes (D1-D5) regulate blood pressure $(78,82)$.

Generally, mood stabilizers do not affect blood pressure, unless chronic renal failure induced by lithium affects volume distribution (1) or these agents cause weight gain (Table 1). Carbamazepine has been associated with acute onset of hypertension in several case reports (83-85). It should be noted that concomitant use of angiotensin-converting enzyme (ACE)-inhibitors or angiotensin II receptor blockers (ARBs) with lithium can lead to acute or chronic lithium toxicity $(86,87)$.

Antidepressants also are associated with only a small increased risk for hypertension $(\mathrm{HR}=1.16, \mathrm{p}<0.001)$ (88) (Table 1). Among antidepressants, TCAs (mainly attributed to the anticholinergic effects of these agents) and serotoninnorepinephrin reuptake inhibitors (SNRIs), particularly venlafaxine, show a significantly higher risk for hypertension with increases up to $15 \mathrm{mmHg}$, while SSRIs do not affect blood pressure (1, 89-91). In addition, bupropion has been shown to increase blood pressure up to $7.5 \mathrm{mmHg}$. The combination bupropion-naltrexone (for the treatment of obesity) also mildly increases blood pressure $(81,92)$.

\section{DIABETES MELLITUS}

The prevalence of type 2 diabetes mellitus (DM) in people with SMI is estimated at $11.3 \%$, which is $2-3$ fold higher than in the general population $(1,29,93,94)$. This figure, however, might even be an underestimate since up to $70 \%$ of SMI patients with DM remain undiagnosed (95-97). There seems to be no difference in DM prevalence rates between schizophrenia, BD or MDD. Multi-episode schizophrenia confers a higher risk for DM than first-episode psychosis. Women also are at higher risk of developing DM (94). Compared with the general population, the onset of DM can occur about 10-20 years earlier in individuals with schizophrenia and BD (93).

\section{Effect of Psychotropic Medication on DM}

Although an association seems to exist between antipsychotic medication and DM, further research is needed to understand how these medications cause $\operatorname{DM}(93,98)$. The estimated prevalence of DM in antipsychotic-naïve patients is $2.9 \%$, which is substantially lower than in patients treated with antipsychotics except for aripiprazole and amisulpride. Treatment duration is associated with higher prevalence rates (94). Particularly olanzapine and clozapine have been linked with a higher risk of glucose dysregulation or DM in people with schizophrenia or $\mathrm{BD}$, followed in ranking by asenapine, paliperidone, quetiapine and risperidone (1, 93, 99, 100). Ziprasidone, lurasidone and aripiprazole are associated with minimal glucose changes, compared to other antipsychotics or placebo (100). Aripiprazole augmentation can lead to slightly reduced glucose levels and improvement in $\mathrm{HbA1c}$, although these improvements are statistically non-significant (51).

A recent meta-analysis (101) confirmed the association between antidepressant use and new-onset DM $(\mathrm{RR}=1.27, \mathrm{p}<0.001)$ that has been found in previous meta-analyses $(102,103)$, reporting a 1.3 to 1.5-fold increase of new-onset DM among antidepressant users, compared with non-users (Table 1). Whether antidepressant use causes DM is still not firmly established $(101,104)$. People with MDD have an increased risk of developing DM (101), while reducing depressive symptoms does lead to better glycemic control independently of weight changes (105). Although it is unclear whether certain antidepressants have a different effect on the risk of DM (101), short-term use of SSRIs in general stabilize or lower blood glucose levels (with a possible risk of hypoglycemia), while TCAs are associated with hyperglycemia and worsening of glycemic control $(99,105,106)$. Particularly people with MDD who have been treated with high or moderate doses for a long time are at an increased of developing DM (106). Whether the concurrent use of (certain) antidepressants is associated with an increased risk of glucose dysregulation or DM remains to be proven $(1,103,104)$. 
Considering mood stabilizers, mixed results are observed (Table 1). On the one hand, no significant change in glucose metabolism has been associated with lithium in several older studies $(69,107,108)$. However, treatment duration can be an important moderator variable as a $0.79 \%$ yearly increase in glucose levels with lithium only seemed to start after a 6-10 years treatment period (109). On the other hand, a recent population based study in $565,253 \mathrm{BD}$ patients without prior glucose metabolism-related diagnoses found that lithium was associated with a decreased risk for developing DM, compared to a "no drug" regimen (110). Regarding valproate, little is known about its effects on glucose metabolism in $\mathrm{BD}$ patients. In patients with epilepsy, it has been established that valproate leads to hyperinsulinemia and insulin resistance after the initial weight gain (111). However, valproate monotherapy was not associated with increased risk for DM in BD patients in a recent study by Nestsiarovich (110). When looking at other antiepileptic agents, both lamotrigine and oxcarbazepine seem to be associated with a reduced risk for DM in the same patient population (110), which is in accordance with earlier studies showing that they either have a positive or neutral effect on glucose metabolism $(112,113)$. Taking into account that many patients with BD need a combination of mood stabilizing agents, antipsychotics and antidepressants, it is disconcerting to note that these combinations lead to a 1.07-2.37 higher risk for DM (110).

\section{Effects of Psychotropic Medication by Age}

As antipsychotic-associated DM is clearly a major issue in adults, it emphasizes the need for an even more judicious use of this class of medications in children and adolescents $(4,10,114)$. Children who are prescribed a SGA have a 2-3 times higher risk of developing type 2 DM, compared with SGA-naive children. Higher cumulative doses (particularly with olanzapine), longer treatment duration, and adjunctive antidepressant use may increase this risk even further, which seems to remain high for a certain period of time after discontinuation (114-116). The metabolic adverse effects during SGA treatment more than likely are mediated by biological or genetic factors, explaining why some children and adolescents are more susceptible to these adverse effects than others $(1,4)$.

Children and adolescents who use antidepressants also appear to have an elevated risk for type $2 \mathrm{DM}(116,117)$. Recent evidence suggests that in antipsychotic-treated youth, concomitant SSRI/SNRI use is associated with an even higher risk of type $2 \mathrm{DM}$, which markedly intensifies with increasing duration of SSRI/SNRI use and cumulative SSRI/SNRI dose (117, 118).

\section{Mechanisms of Medication-Induced DM}

The potential mechanisms for antipsychotic-induced DM include: (1) antipsychotic-induced insulin resistance through weight gain/obesity, (2) insulin resistance due to direct effects of antipsychotics, and (3) antipsychotic-induced $\beta$-cell dysfunction and apoptosis (119). Antipsychotics thus appear to contribute to insulin resistance and DM both indirectly, by inducing weight gain, and directly, by promoting insulin resistance and $\beta$-cell deterioration. M3 receptors play a key role in maintaining proper insulin release through both peripheral and central cholinergic pathways. Olanzapine and clozapine, the SGAs associated with the greatest the risk of DM, also have high binding affinity with M3 receptors (120, 121). Certain genetic polymorphisms can also lead to dysregulated glucose metabolism when combined with antipsychotics (122).

Multiple explanations have been proposed to explain why antidepressant exposure increases the risk of type 2 DM, including antidepressant-induced weight gain, abnormal glucose metabolism through insulin resistance, inhibition of insulin secretion and hyperglycemia, particularly with antidepressants that have a high affinity for the norepinephrine reuptake transporter, serotoninergic 5-HT2C receptor, and histaminergic $\mathrm{H} 1$ receptor (118).

\section{SUMMARY}

Although metabolic abnormalities may be already present in drug naïve SMI patients, reflecting disease-specific mechanisms, it appears that the development of these abnormalities is also attributable to a cumulative long-term effect of unhealthy lifestyle choices and psychotropic medication use, independent of psychiatric disease (123-125). In general, metabolic abnormalities are most common with antipsychotics. Antidepressants and mood stabilizers have a less profound impact on metabolic parameters. However, effects vary greatly with different medications, and interactions with underlying individual factors are relevant. The use of high dosages or multiple medications, as well as the treatment of vulnerable populations seem to be associated with more harmful metabolic consequences.

Screening, assessment, and management of metabolic aspects in patients with SMI remain poor, even in developed countries $(4,11,126)$. It is therefore imperative that psychiatrists, physical health specialists and general practitioners are aware of the interaction between SMI, psychotropics and metabolic abnormalities and collaborate in the integrated care for these patients so that they can receive optimal treatment. Furthermore, governments, insurance companies, health care provider and research funding bodies can take a central role by focusing on implementation of integrated physical and mental health treatment programs, innovations in digital health technologies and ensuring equitable health care access. A blueprint for this worldwide priority for people with SMI has already been conceptualized (127). It is time to put this research into practice.

\section{AUTHOR CONTRIBUTIONS}

VM and JD wrote the first draft. DV, RW, and MH commented on the first draft. MH supervised the writing. All authors contributed to the article and approved the submitted version. 


\section{REFERENCES}

1. Correll CU, Detraux J, De Lepeleire J, De Hert M. Effects of antipsychotics, antidepressants and mood stabilizers on risk for physical diseases in people with schizophrenia, depression and bipolar disorder. World Psychiatry (2015) 14(2):119-36. doi: 10.1002/wps.20204

2. Hayes JF, Miles J, Walters K, King M, Osborn DPJ. A systematic review and meta-analysis of premature mortality in bipolar affective disorder. Acta Psychiatr Scand (2015) 131(6):417-25. doi: 10.1111/acps.12408

3. Walker ER, McGee RE, Druss BG. Mortality in mental disorders and global disease burden implications a systematic review and meta-analysis. JAMA Psychiatry (2015) 72(4):334-41. doi: 10.1001/jamapsychiatry.2014.2502

4. De Hert M, Detraux J. The urgent need for optimal monitoring of metabolic adverse effects in children and youngsters who take on-label or off-label antipsychotic medication. JAMA Psychiatry (2018) 75(8):771-2. doi: 10.1001/jamapsychiatry.2018.1080

5. Maj M, van Os J, De Hert M, Gaebel W, Galderisi S, Green MF, et al. The clinical characterization of the patient with primary psychosis. World Psychiatry (2020).

6. Vohra J. Sudden Cardiac Death in Schizophrenia: A Review. Heart Lung Circ (2020). doi: 10.1016/j.hlc.2020.07.003

7. Pan YJ, Yeh LL, Chan HY, Chang CK. Excess mortality and shortened life expectancy in people with major mental illnesses in Taiwan. Epidemiol Psychiatr Sci (2020) 29(e156):1-11. doi: 10.1017/S2045796020000694

8. Chen WY, Huang SJ, Chang CK, Pan CH, Su SS, Yang TW, et al. Excess mortality and risk factors for mortality among patients with severe mental disorders receiving home care case management. Nord J Psychiatry (2020). doi: 10.1080/08039488.2020.1799431

9. Muntané G, Farré X, Bosch E, Martorell L, Navarro A, Vilella E. The shared genetic architecture of schizophrenia, bipolar disorder and lifespan. Hum Genet (2020). doi: 10.1007/s00439-020-02213-8

10. De Hert M, Correll CU, Bobes J, Cetkovich-Bakmas M, Cohen DAN, Asai I, et al. Physical illness in patients with severe mental disorders. I. Prevalence, impact of medications and disparities in health care. World Psychiatry (2011) 10:52-77. doi: 10.1002/j.2051-5545.2011.tb00014.x

11. De Hert M, Cohen D, Bobes J, Cetkovich-Bakmas M, Leucht S, Ndetei DM, et al. Physical illness in patients with severe mental disorders. II. Barriers to care, monitoring and treatment guidelines, plus recommendations at the system and individual level. World Psychiatry (2011) 10):138-51. doi: 10.1002/j.2051-5545.2011.tb00036.x

12. Rødevand L, Steen NE, Elvsåshagen T, Quintana DS, Reponen EJ, Mørch $\mathrm{RH}$, et al. Cardiovascular risk remains high in schizophrenia with modest improvements in bipolar disorder during past decade. Acta Psychiatr Scand (2019) 139(4):348-60. doi: 10.1111/acps.13008

13. Ng M, Fleming T, Robinson M, Thomson B, Graetz N, Margono C, et al. Global, regional, and national prevalence of overweight and obesity in children and adults during 1980-2013: A systematic analysis for the Global Burden of Disease Study 2013. Lancet (2014) 384(9945):766-81. doi: 10.1016/S0140-6736

14. Collaboration PS. Body-mass index and cause-specific mortality in 900000 adults: collaborative analyses of 57 prospective studies. Lancet (2009) 373:1083-96. doi: 10.1016/S0140-6736(09)60318-4

15. Curran JE, McKay DR, Winkler AM, Olvera RL, Carless MA, Dyer TD, et al. Identification of pleiotropic genetic effects on obesity and brain anatomy. Hum Hered (2013) 75(2-4):136-43. doi: 10.1159/000353953

16. Vancampfort D, Stubbs B, Mitchell AJ, De Hert M, Wampers M, Ward PB, et al. Risk of metabolic syndrome and its components in people with schizophrenia and related psychotic disorders, bipolar disorder and major depressive disorder: A systematic review and meta-analysis. World Psychiatry (2015) 14(3):339-47. doi: 10.1002/wps.20252

17. Teasdale SB, Ward PB, Samaras K, Firth J, Stubbs B, Tripodi E, et al. Dietary intake of people with severe mental illness: Systematic review and metaanalysis. Br J Psychiatry (2019) 214(5):251-9. doi: 10.1192/bjp.2019.20

18. Bak M, Fransen A, Janssen J, Van Os J, Drukker M. Almost all antipsychotics result in weight gain: A meta-analysis. PLoS One (2014) 9(4):1-19. doi: 10.1371/journal.pone.0094112

19. Leucht S, Cipriani A, Spineli L, Mavridis D, Örey D, Richter F, et al. Comparative efficacy and tolerability of 15 antipsychotic drugs in schizophrenia: A multiple-treatments meta-analysis. Lancet (2013) 382 (9896):951-62. doi: 10.1016/S0140-6736(13)60733-3

20. Pillinger T, McCutcheon RA, Vano L, Mizuno Y, Arumuham A, Hindley G, et al. Comparative effects of 18 antipsychotics on metabolic function in patients with schizophrenia, predictors of metabolic dysregulation, and association with psychopathology: a systematic review and network meta-analysis. Lancet Psychiatry (2020) 7(1):64-77. doi: 10.1016/S2215-0366(19)30416-X

21. Reynolds GP, McGowan OO. Mechanisms underlying metabolic disturbances associated with psychosis and antipsychotic drug treatment. J Psychopharmacol (2017) 31(11):1430-6. doi: 10.1177/0269881117722987

22. Tek C, Kucukgoncu S, Guloksuz S, Woods SW, Srihari VH, Annamalai A. Antipsychotic-induced weight gain in first-episode psychosis patients: a meta-analysis of differential effects of antipsychotic medications HHS Public Access. Early Interv Psychiatry (2016) 10(3):193-202. doi: 10.1111/eip.12251

23. De Hert M, Detraux J, Van Winkel R, Yu W, Correll CU. Metabolic and cardiovascular adverse effects associated with antipsychotic drugs. Nat Rev Endocrinol (2012) 8:114-26. doi: 10.1038/nrendo.2011.156

24. Peters T, Nüllig L, Antel J, Naaresh R, Laabs BH, Tegeler L, et al. The Role of Genetic Variation of BMI, Body Composition, and Fat Distribution for Mental Traits and Disorders: A Look-Up and Mendelian Randomization Study. Front Genet (2020) 11(373):1-17. doi: 10.3389/fgene.2020.00373

25. Bahrami S, Steen NE, Shadrin A, O'Connell K, Frei O, Bettella F, et al. Shared Genetic Loci between Body Mass Index and Major Psychiatric Disorders: A Genome-wide Association Study. JAMA Psychiatry (2020) 77(5):503-12. doi: 10.1001/jamapsychiatry.2019.4188

26. Woo YS, McIntyre RS, Kim JB, Lee MS, Kim JM, Yim HW, et al. Association of treatment response with obesity and other metabolic risk factors in adults with depressive disorders: Results from a National Depression Cohort study in Korea (the CRESCEND study). J Affect Disord (2016) 203:190-8. doi: 10.1016/j.jad.2016.06.018

27. Benedetti F, Poletti S, Hoogenboezem TA, Locatelli C, De Wit H, Wijkhuijs AJM, et al. Higher baseline proinflammatory cytokines mark poor antidepressant response in bipolar disorder. J Clin Psychiatry (2017) 78(8): e986-93. doi: 10.4088/JCP.16m11310

28. Nayerifard R, Bureng ma, Zahiroddin A, Namjoo M, Rajezi S. Comparison of metabolic syndrome prevalence in patients with schizophrenia and bipolar I disorder. Diabetes Metab Syndr Clin Res Rev (2017) 11:S411-6. doi: 10.1016/j.dsx.2017.03.027

29. Vancampfort D, Wampers M, Mitchell AJ, Correll CU, De Herdt A, Probst $\mathrm{M}$, et al. A meta-analysis of cardio-metabolic abnormalities in drug naïve, first-episode and multi-episode patients with schizophrenia versus general population controls. World Psychiatry (2013) 12(3):240-50. doi: 10.1002/ wps.20069

30. Alvarez-Jimenez M, Gonzalez-Blanch C, Crespo-Facorro B, Hetrick S, Rodriguez-Sanchez JM, Pérez-Iglesias R, et al. Antipsychotic-Induced Weight Gain in Chronic and First-Episode. CNS Drugs (2008) 22(7):54762. doi: 10.2165/00023210-200822070-00002

31. Salvi V, Mencacci C, Barone-Adesi F. H1-histamine receptor affinity predicts weight gain with antidepressants. Eur Neuropsychopharmacol (2016) 26 (10):1673-7. doi: 10.1016/j.euroneuro.2016.08.0120924-977X/

32. Zai CC, Tiwari AK, Zai GC, Maes MS, Kennedy JL. New findings in pharmacogenetics of schizophrenia. Curr Opin Psychiatry (2018) 31:20012. doi: $10.1097 /$ YCO.0000000000000417

33. Zhang JP, Lencz T, Zhang RX, Nitta M, Maayan L, John $M$, et al. Pharmacogenetic Associations of Antipsychotic Drug-Related Weight Gain: A Systematic Review and Meta-analysis. Schizophr Bull (2016) 42 (6):1418-37. doi: 10.1093/schbul/sbw058

34. Mittal K, Gonçalves VF, Harripaul R, Cuperfain AB, Rollins B, Tiwari AK, et al. A comprehensive analysis of mitochondrial genes variants and their association with antipsychotic-induced weight gain. Schizophr Res (2017) 187:67-73. doi: 10.1016/j.schres.2017.06.046

35. Vancampfort D, Firth J, Correll CU, Solmi M, Siskind D, De Hert M, et al The impact of pharmacological and non-pharmacological interventions to improve physical health outcomes in people with schizophrenia: a metareview of meta-analyses of randomized controlled trials. World Psychiatry (2019) 18(1):53-66. doi: 10.1002/wps.20614

36. de Silva VA, Suraweera C, Ratnatunga SS, Dayabandara M, Wanniarachchi N, Hanwella R. Metformin in prevention and treatment of antipsychotic induced 
weight gain: A systematic review and meta-analysis. BMC Psychiatry (2016) 16(1):341. doi: 10.1186/s12888-016-1049-5

37. Ellul P, Delorme R, Cortese S. Metformin for Weight Gain Associated with Second-Generation Antipsychotics in Children and Adolescents: A Systematic Review and Meta-Analysis. CNS Drugs (2018) 32(12):1103-12. doi: 10.1007/s40263-018-0571-z

38. Maayan L, Vakhrusheva J, Correll CU. Effectiveness of medications used to attenuate antipsychotic-related weight gain and metabolic abnormalities: A systematic review and meta-analysis. Neuropsychopharmacology (2010) 35 (7):1520-30. doi: 10.1038/npp.2010.21

39. Correll CU, Penzner JB, Parikh UH, Mughal T, Javed T, Carbon M, et al. Recognizing and monitoring adverse events of second-generation antipsychotics in children and adolescents. Child Adolesc Psychiatr Clinics North America (2006) 15:177-206. doi: 10.1016/j.chc.2005. 08.007

40. De Hert M, Dobbelaere M, Sheridan EM, Cohen D, Correll CU. Metabolic and endocrine adverse effects of second-generation antipsychotics in children and adolescents: A systematic review of randomized, placebo controlled trials and guidelines for clinical practice. Eur Psychiatry Eur Psychiatry (2011) 26:144-58. doi: 10.1016/j.eurpsy.2010.09.011

41. Fraguas D, Correll CU, Merchán-Naranjo J, Rapado-Castro M, Parellada M, Moreno C, et al. Efficacy and safety of second-generation antipsychotics in children and adolescents with psychotic and bipolar spectrum disorders: Comprehensive review of prospective head-to-head and placebo-controlled comparisons. Eur Neuropsychopharmacol (2011) 21:621-45. doi: 10.1016/ j.euroneuro.2010.07.002

42. Pagsberg AK, Tarp S, Glintborg D, Stenstrøm AD, Fink-Jensen A, Correll $\mathrm{CU}$, et al. Acute Antipsychotic Treatment of Children and Adolescents With Schizophrenia-Spectrum Disorders: A Systematic Review and Network Meta-Analysis. J Am Acad Child Adolesc Psychiatry (2017) 56(3):191-202. doi: 10.1016/j.jaac.2016.12.013

43. Pringsheim T, Lam D, Ching H, Patten S. Metabolic and neurological complications of second-generation antipsychotic use in children: A systematic review and meta-analysis of randomized controlled trials. Drug Saf (2011) 34(8):651-68. doi: 10.2165/11592020-000000000-00000

44. Ahmad S, Ahluwalia TS. Editorial: The role of genetic and lifestyle factors in metabolic diseases. Front Endocrinol (Lausanne) (2019) 10(JULY):1-3. doi: 10.3389/fendo.2019.00475

45. Pérez-Iglesias R, Martínez-García O, Pardo-Garcia G, Amado JA, GarciaUnzueta MT, Tabares-Seisdedos R, et al. Course of weight gain and metabolic abnormalities in first treated episode of psychosis: The first year is a critical period for development of cardiovascular risk factors. Int J Neuropsychopharmacol (2014) 17(1):41-51. doi: 10.1017/S1461145713001053

46. Okbay A, Baselmans BML, De Neve JE, Turley P, Nivard MG, Fontana MA, et al. Genetic variants associated with subjective well-being, depressive symptoms, and neuroticism identified through genome-wide analyses. Nat Genet (2016) 48(6):624-33. doi: 10.1038/ng.3552

47. Mitchell AJ, Vancampfort D, Sweers K, Van Winkel R, Yu W, De Hert M. Prevalence of metabolic syndrome and metabolic abnormalities in schizophrenia and related disorders-a systematic review and meta-analysis. Schizophr Bull (2013) 39(2):306-18. doi: 10.1093/schbul/sbr148

48. Mitchell AJ, Vancampfort D, De Herdt A, Yu W, De Hert M. Is the prevalence of metabolic syndrome and metabolic abnormalities increased in early schizophrenia? a comparative meta-analysis of first episode, untreated and treated patients. Schizophr Bull (2013) 39(2):295-305. doi: $10.1093 / \mathrm{schbul} / \mathrm{sbs} 082$

49. Vancampfort D, Vansteelandt K, Correll CU, Mitchell AJ, De Herdt A, Sienaert $\mathrm{P}$, et al. Metabolic syndrome and metabolic abnormalities in bipolar disorder: A meta-analysis of prevalence rates and moderators. Am J Psychiatry (2013) 170:265-74. doi: 10.1176/appi.ajp.2012.12050620

50. Guha P, Bhowmick K, Mazumder P, Ghosal M, Chakraborty I, Burman P. Assessment of insulin resistance and metabolic syndrome in drug naive patients of bipolar disorder. Indian J Clin Biochem (2014) 29(1):51-6. doi: 10.1007/s12291-012-0292-x

51. Ijaz S, Bolea B, Davies S, Savović J, Richards A, Sullivan S, et al. Antipsychotic polypharmacy and metabolic syndrome in schizophrenia: A review of systematic reviews. BMC Psychiatry (2018) 18(1):275. doi: 10.1186/s12888-018-1848-y
52. Vancampfort D, Correll CU, Wampers M, Sienaert P, Mitchell AJ, De Herdt A, et al. Metabolic syndrome and metabolic abnormalities in patients with major depressive disorder: A meta-analysis of prevalences and moderating variables. Psychol Med (2014) 44(10):2017-28. doi: 10.1017/S0033291713002778

53. Gramaglia C, Gambaro E, Bartolomei G, Camera P, Chiarelli-Serra M, Lorenzini L, et al. Increased Risk of Metabolic Syndrome in Antidepressants Users: A Mini Review. Front Psychiatry (2018) 9:621. doi: 10.3389/ fpsyt.2018.00621

54. Penninx BWJH, Lange SMM. Metabolic syndrome in psychiatric patients: Overview, mechanisms, and implications. Dialogues Clin Neurosci (2018) 20 (1):63-73.

55. Pan A, Keum N, Okereke OI, Sun Q, Kivimaki M, Rubin RR, et al. Bidirectional association between depression and metabolic syndrome: A systematic review and meta-analysis of epidemiological studies. Diabetes Care (2012) 35(5):1171-80. doi: 10.2337/dc11-2055/-/DC1

56. Rhee SJ, Kim EY, Kim SH, Lee HJ, Kim B, Ha K, et al. Subjective depressive symptoms and metabolic syndrome among the general population. Prog Neuropsychopharmacol Biol Psychiatry (2014) 54:223-30. doi: 10.1016/ j.pnpbp.2014.06.006

57. Hiles SA, Révész D, Lamers F, Giltay E, Penninx BWJH. Bidirectional prospective associations of metabolic syndrome components with depression, anxiety and antidepressant use. Depress Anxiety (2016) 33 (8):754-64. doi: 10.1002/da.22512

58. Pyykkönen AJ, Räikkönen K, Tuomi T, Eriksson JG, Groop L, Isomaa B. Association between depressive symptoms and metabolic syndrome is not explained by antidepressant medication: Results from the PPP-Botnia Study. Ann Med (2012) 44(3):279-88. doi: 10.3109/07853890.2010.543921

59. Misiak B, Stańczykiewicz B, Łaczmański E, Frydecka D. Lipid profile disturbances in antipsychotic-naive patients with first-episode nonaffective psychosis: A systematic review and meta-analysis. Schizophr Res (2017) 190):18-27. doi: 10.1016/j.schres.2017.03.031

60. Andreassen OA, Djurovic S, Thompson WK, Schork AJ, Kendler KS, O'Donovan MC, et al. Improved detection of common variants associated with schizophrenia by leveraging pleiotropy with cardiovascular-disease risk factors. Am J Hum Genet (2013) 92(2):197-209. doi: 10.1016/j.ajhg. 2013.01.001

61. Moreira FP, Jansen K, Cardoso T de A, Mondin TC, Magalhães PV da S, Kapczinski F, et al. Metabolic syndrome in subjects with bipolar disorder and major depressive disorder in a current depressive episode: Populationbased study: Metabolic syndrome in current depressive episode. J Psychiatr Res (2017) 92:119-23. doi: 10.1016/j.jpsychires.2017.03.025

62. Coello K, Vinberg M, Knop FK, Pedersen BK, McIntyre RS, Kessing LV, et al. Metabolic profile in patients with newly diagnosed bipolar disorder and their unaffected first-degree relatives. Int J Bipolar Disord (2019) 7(1):8. doi: 10.1186/s40345-019-0142-3

63. Huang YJ, Tsai SY, Chung KH, Chen PH, Huang SH, Kuo CJ. Statedependent alterations of lipid profiles in patients with bipolar disorder. Int $J$ Psychiatry Med (2018) 53(4):273-81. doi: 10.1177/0091217417749786

64. Amare AT, Schubert KO, Klingler-Hoffmann M, Cohen-Woods S, Baune BT. The genetic overlap between mood disorders and cardiometabolic diseases: A systematic review of genome wide and candidate gene studies. Trans Psychiatry (2017) 7(1):e1007. doi: 10.1101/150615

65. Buhagiar K, Jabbar F. Association of First- vs. Second-Generation Antipsychotics with Lipid Abnormalities in Individuals with Severe Mental Illness: A Systematic Review and Meta-Analysis. Clin Drug Invest (2019) 39:253-73. doi: 10.1007/s40261-019-00751-2

66. De Hert M, Kalnicka D, van Winkel R, Wampers M, Hanssens L, Van Eyck D, et al. Treatment With Rosuvastatin for Severe Dyslipidemia in Patients With Schizophrenia and Schizoaffective Disorder. JClin Psychiatry (2006) 67 (12):1889-96. doi: 10.4088/JCP.v67n1208

67. Zheng W, Yang W, Zhang QE, Yang XH, Cai DB, H JQ, et al. Meta-analysis of the Efficacy and Safety of Adjunctive Rosuvastatin for Dyslipidemia in Patients with Schizophrenia. Shanghai Arch Psychiatry (2018) 30:4-11. doi: 10.11919/j.issn.1002-0829.217156

68. Hanssens L, De Hert M, Kalnicka D, Van Winkel R, Wampers M, Van Eyck $\mathrm{D}$, et al. Pharmacological treatment of severe dyslipidaemia in patients with schizophrenia. Int Clin Psychopharmacol (2007) 22(1):43-9. doi: 10.1097/ YIC.0b013e3280113d3b 
69. McIntyre RS, McElroy SL, Eudicone JM, Forbes RA, Carlson BX, Baker RA. A 52-week, double-blind evaluation of the metabolic effects of aripiprazole and lithium in bipolar I disorder. Prim Care Companion J Clin Psychiatry (2011) 13(6):PCC.11m01182. doi: 10.4088/PCC.11m01182

70. Geller B, Luby JL, Joshi P, Wagner KD, Emslie G, Walkup JT, et al. A randomized controlled trial of risperidone, lithium, or divalproex sodium for initial treatment of bipolar I disorder, manic or mixed phase, in children and adolescents. Arch Gen Psychiatry (2012) 69(5):515-28. doi: 10.1001/ archgenpsychiatry.2011.1508

71. Redden L, Delbello M, Wagner KD, Wilens TE, Malhotra S, Wozniak P, et al. Long-term safety of divalproex sodium extended-release in children and adolescents with bipolar I disorder. J Child Adolesc Psychopharmacol (2009) 19(1):83-9. doi: 10.1089/cap.2008.0106

72. Post RM, Ketter TA, Uhde T, Ballenger JC. Thirty years of clinical experience with carbamazepine in the treatment of bipolar illness: Principles and practice. CNS Drugs (2007) 21:47-71. doi: 10.2165/00023210-20072101000005

73. Fjukstad KK, Engum A, Lydersen S, Dieset I, Steen NE, Andreassen OA, et al. Metabolic Abnormalities Related to Treatment with Selective Serotonin Reuptake Inhibitors in Patients with Schizophrenia or Bipolar Disorder. J Clin Psychopharmacol (2016) 36(6):615-20. doi: 10.1097/JCP.0000000000000582

74. Fjukstad KK, Engum A, Lydersen S, Dieset I, Steen NE, Andreassen OA, et al. Metabolic risk factors in schizophrenia and bipolar disorder: The effect of comedication with selective serotonin reuptake inhibitors and antipsychotics. Eur Psychiatry (2018) 48:71-8. doi: 10.1016/ j.eurpsy.2017.04.001

75. Ayerbe L, Forgnone I, Addo J, Siguero A, Gelati S, Ayis S. Hypertension risk and clinical care in patients with bipolar disorder or schizophrenia; a systematic review and meta-analysis. J Affect Disord (2018) 225:665-70. doi: 10.1016/j.jad.2017.09.002

76. Chen Y-L, Pan C-H, Chang C-K, Chen P-H, Chang H-M, Tai M-H, et al. Physical Illnesses Before Diagnosed as Schizophrenia: A Nationwide CaseControl Study. Schizophr Bull (2020) 46(4):785-94. doi: 10.1093/schbul/ sbaa009

77. Fugger G, Dold M, Bartova L, Kautzky A, Souery D, Mendlewicz J, et al. Comorbid hypertension in patients with major depressive disorder-Results from a European multicenter study. Eur Neuropsychopharmacol (2019) 29:777-85. doi: 10.1016/j.euroneuro.2019.03.005

78. Alves BB, Oliveira G de P, Moreira Neto MG, Fiorilli RB, Cestário E do ES. Use of atypical antipsychotics and risk of hypertension: A case report and review literature. SAGE Open Med Case Rep (2019) 7:2050313X1984182. doi: 10.1177/2050313X19841825

79. Henderson DC, Daley TB, Kunkel L, Rodrigues-Scott M, Koul P, Hayden D. Clozapine and hypertension: A chart review of 82 patients. J Clin Psychiatry (2004) 65(5):686-9. doi: 10.4088/JCP.v65n0514

80. Correll CU, Joffe BI, Rosen LM, Sullivan TB, Joffe RT. Cardiovascular and cerebrovascular risk factors and events associated with second-generation antipsychotic compared to antidepressant use in a non-elderly adult sample: Results from a claims-based inception cohort study. World Psychiatry (2015) 14(1):56-63. doi: 10.1002/wps.20187

81. Cohen JB, Gadde KM. Weight Loss Medications in the Treatment of Obesity and Hypertension. Curr Hypertens Rep (2019) 21(2):16. doi: 10.1007/ s11906-019-0915-1

82. Gonsai NH, Amin VH, Mendpara CG, Speth R, Hale GM. Effects of dopamine receptor antagonist antipsychotic therapy on blood pressure. J Clin Pharm Ther (2018) 43(1):1-7. doi: 10.1111/jcpt.12649

83. Ubaid A, Waheed F, Waheed S. Carbamazepine-Induced Uncontrolled Hypertension. Am J Ther (2019) 10. doi: 10.1097/MJT.0000000000001055

84. Jette N, Veregin T, Guberman A. Carbamazepine-induced hypertension. Neurology (2002) 59(2):275-6. doi: 10.1212/WNL.59.2.275

85. Kharb P, Mittal N, Gupta MC. Carbamazepine-induced hypertension: A rare case. J Pharmacol Pharmacother (2015) 6(4):216-8. doi: 10.4103/0976500X.171879

86. Masiran R, Abdul Aziz MF. Hypertensive bipolar: chronic lithium toxicity in patients taking ACE inhibitor. BMJ Case Rep (2017) 2017:bcr2017220631. doi: 10.1136/bcr-2017-220631

87. Finley PR, O'Brien JG, Coleman RW. Lithium and angiotensin-converting enzyme inhibitors: Evaluation of a potential interaction. J Clin
Psychopharmacol (1996) 16(1):68-71. doi: 10.1097/00004714-19960200000011

88. Kao W-T, Chang C-L, Lin C-H, Wu S-L, Lin S-L, Lung F-W. Gender Disparity in the Risk of Hypertension in Subjects With Major Depressive Disorder. Front Psychiatry (2019) 10(August 2019):1-9. doi: 10.3389/ fpsyt.2019.00541

89. Carvalho AF, Sharma MS, Brunoni AR, Vieta E, Fava GA. The Safety, Tolerability and Risks Associated with the Use of Newer Generation Antidepressant Drugs: A Critical Review of the Literature. Psychother Psychosom (2016) 85(5):270-88. doi: 10.1159/000447034

90. Manolis TA, Manolis AA, Manolis AS. Cardiovascular Safety of Psychiatric Agents: A Cautionary Tale. Angiology (2019) 70(2):103-29. doi: 10.1177/ 0003319718780145

91. Zhong Z, Wang L, Wen X, Liu Y, Fan Y, Liu Z. A meta-analysis of effects of selective serotonin reuptake inhibitors on blood pressure in depression treatment: Outcomes from placebo and serotonin and noradrenaline reuptake inhibitor controlled trials. Neuropsychiatr Dis Treat (2017) 13:2781-96. doi: 10.2147/NDT.S141832

92. Teply RM, Packard KA, White ND, Hilleman DE, DiNicolantonio JJ. Treatment of Depression in Patients with Concomitant Cardiac Disease. Prog Cardiovasc Dis (2016) 58(5):514-28. doi: 10.1016/j.pcad.2015.11.003

93. Holt RIG, Mitchell AJ. Diabetes mellitus and severe mental illness: Mechanisms and clinical implications. Nat Rev Endocrinol (2015) 11 (2):79-89. doi: 10.1038/nrendo.2014.203

94. Vancampfort D, Correll CU, Galling B, Probst M, De Hert M, Ward PB, et al. Diabetes mellitus in people with schizophrenia, bipolar disorder and major depressive disorder: A systematic review and large scale meta-analysis. World Psychiatry (2016) 15(2):166-74. doi: 10.1002/wps.20309

95. Subramaniam M, Chong S-A, Pek E. Diabetes mellitus and impaired glucose tolerance in patients with schizophrenia. Can J Psychiatry (2003) 48(5):3457. doi: $10.1177 / 070674370304800512$

96. Taylor D, Young C, Mohamed R, Paton C, Walwyn R. Undiagnosed impaired fasting glucose and diabetes mellitus amongst inpatients receiving antipsychotic drugs. J Psychopharmacol (2005) 19(2):182-6. doi: $10.1177 / 0269881105049039$

97. Voruganti LP, Punthakee Z, Van Lieshout RJ, MacCrimmon D, Parker G, Awad AG, et al. Dysglycemia in a community sample of people treated for schizophrenia: The Diabetes in Schizophrenia in Central-south Ontario (DiSCO) study. Schizophr Res (2007) 96:215-22. doi: 10.1016/ j.schres.2007.07.016

98. Whicher CA, Price HC, Holt RIG. Antipsychotic medication and type 2 diabetes and impaired glucose regulation. Eur J Endocrinol (2018) 178(6): R245-58. doi: 10.1530/EJE-18-0022

99. Abosi O, Lopes S, Schmitz S, Fiedorowicz JG. Cardiometabolic effects of psychotropic medications. Horm Mol Biol Clin Invest (2018) 36(1). doi: 10.1515/hmbci-2017-0065

100. Zhang Y, Liu Y, Su Y, You Y, Ma Y, Yang G, et al. The metabolic side effects of 12 antipsychotic drugs used for the treatment of schizophrenia on glucose: A network meta-analysis. BMC Psychiatry (2017) 17(1):373. doi: 10.1186/ s12888-017-1539-0

101. Salvi V, Grua I, Cerveri G, Mencacci C, Barone-Adesi F. The risk of new-onset diabetes in antidepressant users - A systematic review and meta-analysis. PLoS One (2017) 12(7):e0182088. doi: 10.1371/journal.pone.0182088

102. Bhattacharjee S, Bhattacharya R, Kelley GA, Sambamoorthi U. Antidepressant use and new-onset diabetes: A systematic review and meta-analysis. Diabetes Metab Res Rev (2013) 29(4):273-84. doi: 10.1002/dmrr.2393

103. Yoon JM, Cho EG, Lee HK, Park SM. Antidepressant use and diabetes mellitus risk: A meta-analysis. Korean J Fam Med (2013) 34(4):228-40. doi: $10.4082 / \mathrm{kjfm} .2013 .34 .4 .228$

104. Barnard K, Peveler RC, Holt RIG. Antidepressant medication as a risk factor for type 2 diabetes and impaired glucose regulation. Diabetes Care (2013) 36 (10):3337-45. doi: 10.2337/dc13-0560

105. Roopan S, Larsen ER. Use of antidepressants in patients with depression and comorbid diabetes mellitus: A systematic review. Acta Neuropsychiatr (2017) 29(3):127-39. doi: 10.1017/neu.2016.54

106. Fathallah N, Slim R, Larif S, Hmouda H, Ben Salem C. Drug-Induced Hyperglycaemia and Diabetes. Drug Saf (2015) 38(12):1153-68. doi: 10.1007/s40264-015-0339-z 
107. Aprahamian I, Santos FS, Dos Santos B, Talib L, Diniz BS, Radanovic M, et al. Long-term, low-dose lithium treatment does not impair renal function in the elderly: A 2-year randomized, placebo-controlled trial followed by single-blind extension. J Clin Psychiatry (2014) 75(7):672-8. doi: 10.4088/ JCP. $13 \mathrm{~m} 08741$

108. Vestergaard P, Schou M. Does long-term lithium treatment induce diabetes mellitus. Neuropsychobiology (1987) 17(3):130-2. doi: 10.1159/000118351

109. Tondo L, Abramowicz M, Alda M, Bauer M, Bocchetta A, Bolzani L, et al. Long-term lithium treatment in bipolar disorder: effects on glomerular filtration rate and other metabolic parameters. Int J Bipolar Disord (2017) 5(1):27. doi: 10.1186/s40345-017-0096-2

110. Nestsiarovich A, Kerner B, Mazurie AJ, Cannon DC, Hurwitz NG, Zhu Y, et al. Diabetes mellitus risk for 102 drugs and drug combinations used in patients with bipolar disorder. Psychoneuroendocrinology (2020) 112:104511. doi: 10.1016/j.psyneuen.2019.104511

111. Belcastro V, D'Egidio C, Striano P, Verrotti A. Metabolic and endocrine effects of valproic acid chronic treatment. Epilepsy Res (2013) 107:1-8. doi: 10.1016/j.eplepsyres.2013.08.016

112. Rättyä J, Vainionpa L, Knip M, Lanning P, Isojärvi JIT. The effects of valproate, carbamazepine, and oxcarbazepine on growth and sexual maturation in girls with epilepsy. Pediatrics (1999) 103(3):588-93. doi: 10.1542/peds.103.3.588

113. Cansu A, Serdaroglu A, Cinaz P. Serum insulin, cortisol, leptin, neuropeptide $\mathrm{Y}$, galanin and ghrelin levels in epileptic children receiving oxcarbazepine. Eur J Paediatr Neurol (2011) 15(6):527-31. doi: 10.1016/j.ejpn.2011.05.004

114. Nicol GE, Yingling MD, Flavin KS, Schweiger JA, Patterson BW, Schechtman KB, et al. Metabolic effects of antipsychotics on adiposity and insulin sensitivity in youths a randomized clinical trial. JAMA Psychiatry (2018) 75(8):788-96. doi: 10.1001/jamapsychiatry.2018.1088

115. Pisano S, Catone G, Veltri S, Lanzara V, Pozzi M, Clementi E, et al. Update on the safety of second generation antipsychotics in youths: A call for collaboration among paediatricians and child psychiatrists. Ital J Pediatr (2016) 42(1):51. doi: 10.1186/s13052-016-0259-2

116. Rubin DM, Kreider AR, Matone M, Huang YS, Feudtner C, Ross ME, et al. Risk for incident diabetes mellitus following initiation of second-generation antipsychotics among medicaid-enrolled youths. JAMA Pediatr (2015) 169 (4):e150285. doi: 10.1001/jamapediatrics.2015.0285

117. Correll CU, Galling B. Polypharmacy in Youth Treated With Antipsychotics: Do Antidepressants or Stimulants Add to the Risk for Type 2 Diabetes? J Am Acad Child Adolesc Psychiatry (2017) 56:634-5. doi: 10.1016/j.jaac.2017.05.017

118. Burcu M, Zito JM, Safer DJ, Magder LS, DosReis S, Shaya FT, et al. Concomitant Use of Atypical Antipsychotics With Other Psychotropic Medication Classes and the Risk of Type 2 Diabetes Mellitus. J Am Acad Child Adolesc Psychiatry (2017) 56(8):642-51. doi: 10.1016/j.jaac.2017.04.004
119. Chen J, Huang XF, Shao R, Chen C, Deng C. Molecular mechanisms of antipsychotic drug-induced diabetes. Front Neurosci (2017) 11(643). doi: $10.3389 /$ fnins.2017.00643

120. Weston-Green K, Huang XF, Deng C. Second generation antipsychoticinduced type 2 diabetes: A role for the muscarinic M3 receptor. CNS Drugs (2013) 27:1069-80. doi: 10.1007/s40263-013-0115-5

121. Deng C. Effects of Antipsychotic Medications on Appetite, Weight, and Insulin Resistance. Endocrinol Metab Clin North Am (2013) 42(3):545-63. doi: 10.1016/j.ecl.2013.05.006

122. Liu MZ, He HY, Luo JQ, He FZ, Chen ZR, Liu YP, et al. Drug-induced hyperglycaemia and diabetes: pharmacogenomics perspectives. Arch Pharm Res (2018) 41(7):725-36. doi: 10.1007/s12272-018-1039-x

123. Burghardt KJ, Seyoum B, Mallisho A, Burghardt PR, Kowluru RA, Yi Z. Atypical antipsychotics, insulin resistance and weight; A meta-analysis of healthy volunteer studies. Prog Neuropsychopharmacol Biol Psychiatry (2018) 83:55-63. doi: 10.1016/j.pnpbp.2018.01.004

124. Ragguett RM, Hahn M, Messina G, Chieffi S, Monda M, De Luca V. Association between antipsychotic treatment and leptin levels across multiple psychiatric populations: An updated meta-analysis. Hum Psychopharmacol (2017) 32(6). doi: 10.1002/hup.2631

125. Singh VK, Karmani S, Malo PK, Virupaksha HG, Muralidhar D, Venkatasubramanian $G$, et al. Impact of lifestyle modification on some components of metabolic syndrome in persons with severe mental disorders: A meta-analysis. Schizophr Res (2018) 202:17-25. doi: 10.1016/ j.schres.2018.06.066

126. de Hert M, Detraux J. Reversing the downward spiral for people with severe mental illness through educational innovations. World Psychiatry (2017) 16 (1):41-2. doi: 10.1002/wps.20377

127. Firth J, Siddiqi N, Koyanagi A, Siskind D, Rosenbaum S, Galletly C, et al. The Lancet Psychiatry Commission: a blueprint for protecting physical health in people with mental illness. Lancet Psychiatry (2019) 6:675-712. doi: 10.1016/ S2215-0366(19)30387-6

Conflict of Interest: The authors declare that the research was conducted in the absence of any commercial or financial relationships that could be construed as a potential conflict of interest.

Copyright (C) 2020 Mazereel, Detraux, Vancampfort, van Winkel and De Hert. This is an open-access article distributed under the terms of the Creative Commons Attribution License (CC BY). The use, distribution or reproduction in other forums is permitted, provided the original author(s) and the copyright owner(s) are credited and that the original publication in this journal is cited, in accordance with accepted academic practice. No use, distribution or reproduction is permitted which does not comply with these terms. 